\title{
The GC-IGF1 axis-mediated testicular dysplasia caused by prenatal caffeine exposure
}

\author{
Lin-guo Pei1,2,*, Qi Zhang1,*, Chao Yuan¹, Min Liu¹, Yun-fei Zou¹, Feng Lv1, Da-ji Luo³, Shan Zhong³ and Hui Wang1,3 \\ 1Department of Pharmacology, Basic Medical School of Wuhan University, Wuhan, China \\ Basic Medical College of Nanyang Medical University, Nanyang, China \\ ${ }^{3}$ Hubei Provincial Key Laboratory of Developmentally Originated Disease, Wuhan, China \\ Correspondence should be addressed to H Wang: wanghui19@whu.edu.cn \\ *(L Pei and Q Zhang contributed equally to this work) \\ This paper is part of a thematic section on 30 Years of the Developmental Origins of Health and Disease. The guest editors for this section were Sean \\ Limesand, Kent Thornburg and Jane Harding
}

\begin{abstract}
Prenatal caffeine exposure (PCE) can induce testicular developmental toxicity. Here, we aimed to explore the underlying mechanism of this process in reference to its intrauterine origin. Pregnant rats were intragastrically administrated caffeine (30 and $120 \mathrm{mg} / \mathrm{kg} /$ day) from gestational days 9 to 20 . The results showed that the male fetuses exposed to high dose of caffeine $(120 \mathrm{mg} / \mathrm{kg} /$ day) had a decreased bodyweight and inhibited testosterone synthetic function. Meanwhile, their serum corticosterone concentration was elevated and their testicular insulin-like growth factor 1 (Igf1) expression was decreased. Moreover, the histone 3 lysine 14 acetylation (H3K14ac) level in the Igf1 promoter region was reduced. Low-dose (30 mg/kg/day) caffeine exposure, however, increased steroidogenic enzymes expression in male fetuses. After birth, the serum corticosterone concentration gradually decreased in the PCE $(120 \mathrm{mg} / \mathrm{kg} / \mathrm{day})$ offspring rats, whereas the expression and H3K14ac level of Igf1 gradually increased, with obvious catch-up growth and testicular development compensation. Intriguingly, when we subjected the offspring to 2 weeks of chronic stress to elevate the serum corticosterone concentration, the expression of Igf1 and testosterone synthesis were inhibited again in the PCE (120 mg/kg/day) group, accompanied by a decrease in the H3K14ac level in the Igf1 promoter region. In vitro, corticosterone (rather than caffeine) was proved to inhibit testosterone production in Leydig cells by altering the H3K14ac level and the expression of Igf1. These observations suggested that PCE-induced testicular developmental toxicity is related to the negative regulation of corticosterone on H3K14ac levels and the expression of Igf1.
\end{abstract}

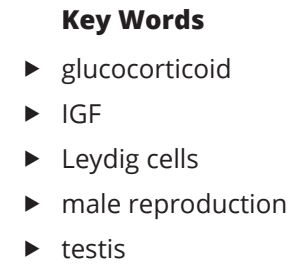

Journal of Endocrinology (2019) 242, M17-M32

\section{Introduction}

Caffeine, which is a common component of foods, beverages and pharmaceuticals, is widely ingested by people, even pregnant women (Fredholm et al. 1999, Kluger 2004). Approximately $75 \%$ of women consume caffeine during pregnancy in the United States (Signorello \& McLaughlin 2004). Previous studies have indicated that prenatal caffeine exposure (PCE) resulted in adverse birth outcomes, including intrauterine growth 
retardation (IUGR) (Fortier et al. 1993, Chen et al. 2014, Greenwood et al. 2014). There is evidence that caffeine intake of $300 \mathrm{mg} /$ day in pregnant women is associated with an increased risk of IUGR according to the World Health Organization (WHO) (Guilbert 2003). However, there are some pregnant women whose caffeine intake exceeds this level ( $>300 \mathrm{mg} /$ day), and may even reach $500 \mathrm{mg} /$ day (CARE Study Group 2008). In addition, PCE has irreversible effects on reproductive parameters and fertility in males (Ramlau-Hansen et al. 2008, Dorostghoal et al. 2012, Cavalcante et al. 2014). IUGR refers to the poor growth of a baby while in the mother's womb during pregnancy. IUGR is believed to put infants at risk for adult reproductive disorders and testicular dysplasia (Francois et al. 1997, Moller \& Skakkebaek 1997). Despite the known negative effects of PCE and IUGR on testicular development, the underlying mechanism in reference to its intrauterine origin has not been clarified.

Androgens, which are primarily released from Leydig cells (LCs), are synthesized from cholesterol under the catalysis of a plurality of steroid synthetases. Deficient androgen action is important in the origin of male reproductive disorders and in programming male reproductive dysfunctions (Macleod et al. 2010). A deficiency in androgens can further induce disease states of the body, such as obesity and insulin resistance (Cohen 1999, Pitteloud et al. 2005). Thus, an appropriate level of androgens must be maintained. The role of insulin-like growth factor 1 (IGF1) has been demonstrated in the regulation of testis development, number of LCs and steroidogenesis (Wang et al. 2003). The deletion of Igf1 was shown to result in diminished number of LCs and lower circulating testosterone level in adult males (Wang \& Hardy 2004). Our previous studies found that PCEinduced maternal glucocorticoid overexposure in fetal rats and inhibited the expression of $I g f 1$ in a variety of tissues (Tan et al. 2012, Wang et al. 2014, Chen et al. 2018). Therefore, it is reasonable to speculate that the effect of PCE on testicular development may be influenced by fetal blood glucocorticoid level and local Igf1 expression.

Altered fetal growth or development can fundamentally change the risk of health disorders in adulthood and perhaps, in future generations (Aiken \& Ozanne 2014). This phenomenon is called 'intrauterine programming'. Indeed, early-life events will trigger changes in fetal development trajectory that remain in specific circumstances after birth (Fowden et al. 2008). Increasing studies have reported that excessive glucocorticoid exposure is a key initiating factor of intrauterine programming (Moisiadis \& Matthews 2014a,b), and these changes likely involve epigenetic processes (Crudo et al. 2013). A study of IUGR in rats found that alterations to the histone code were responsible for reduced Igf1 expression (Fu et al. 2009). Evidence from our laboratory also revealed that histone modification played a role in the permanent reprogramming of the genome in response to PCE (Tan et al. 2012). These results suggest that the high glucocorticoid level induced by PCE may program IGF1 expression in the testis through an epigenetic mechanism.

In this study, pregnant rats were treated with different doses of caffeine during middle and late pregnancy as our previous study described (Ao et al. 2015, Shangguan et al. 2017). By detecting the morphological and functional indexes in male offspring rats, we aimed to confirm the presence of testicular development toxicity and explore its intrauterine programming mechanism by PCE. Moreover, by combining a chronic stress model in vivo and cell experiment in vitro, we clarified a glucocorticoidmediated intrauterine programming mechanism of IGF1 and testosterone synthesis. This study elucidates the glucocorticoid-insulin-like growth factor 1 (GC-IGF1) axis-related intrauterine programming mechanism for testicular development toxicity and provides an experimental and theoretical basis for the early prevention and treatment of testicular development toxicity-related diseases.

\section{Materials and methods}

\section{Chemicals and reagents}

Caffeine (CAS\#58-08-2) was purchased from SigmaAldrich Co., Ltd. Isoflurane was purchased from Baxter Healthcare Co. (Deerfield, IL, USA). The ELISA kits for rat corticosterone and testosterone were obtained from R\&D Systems, Inc. Rat radioimmunoassay kit (lot number: 20160620) was purchased from Beijing North Institute of Biological Technology (Beijing, China). Primary antibodies such as goat anti-rabbit immunoglobulin G (IgG) (ab172730) and anti-Ki67 (ab15580) were purchased from Abcam. 33-Hydroxysteroid dehydrogenase (HSD3B) antibody (sc-30820) and IGF1 antibody (sc-9013) were purchased from Santa Cruz Biotechnology, Inc. $\beta$-Actin (AC004) was purchased from ABclonal Technology (Wuhan, China). The antibodies for histone 3 lysine 9 acetylation (H3K9ac) (A7255) and histone 3 lysine 14 acetylation (H3K14ac) (A7254) were also purchased from ABclonal Technology. Specific antibody information is provided in Supplementary Table 1 (see section on 
supplementary data given at the end of this article). Chromatin immunoprecipitation (ChIP) assay kits were purchased from Millipore Co., Ltd. Mifepristone (RU486) (ODR-4395) and proteinase $\mathrm{K}(20 \mathrm{mg} / \mathrm{kg})$ (ST533) were purchased from Kori Biotech Co., Ltd (Wuhan, China). IGF1 (791-MG) was purchased from Abcam. Reverse transcription and real-time quantitative polymerase chain reaction (RT-qPCR) kits were purchased from Takara Biotechnology Co., Ltd. The SYBR green dye was purchased from Applied Biosystems (Thermo Fisher Scientific). All of the primers were synthesized by Sangon Biotech Co., Ltd. (Shanghai, China).

\section{Animals and treatment}

The animal experiments were performed in the Center for Animal Experiments of Wuhan University, which has been accredited by the Association for Assessment and Accreditation of Laboratory Animal Care International (AAALAC International). The protocol was approved by the Committee on the Ethics of Animal Experiments of the Wuhan University School of Medicine (Permit No. 201709). All animal experimental procedures were performed in accordance with the Guidelines for the Care and Use of Laboratory Animals of the Chinese Animal Welfare Committee. To reduce bias in the animal experiments, the rats were housed and treated by a technician, and different co-authors were in charge of testis and blood sample harvesting and data analysis, respectively. The experimental procedures and treatment methods in this study were described as follows (Supplementary Fig. 1).

The Wistar rats raised in this study were bred and mated as previously described (Xu et al. 2012b). The rat dams were randomly distributed into three groups: a control group, a low-dose $(30 \mathrm{mg} / \mathrm{kg} /$ day) caffeine exposure (PCE(L)) group and a high-dose $(120 \mathrm{mg} / \mathrm{kg} / \mathrm{day})$ caffeine exposure $(\mathrm{PCE}(\mathrm{H}))$ group. From gestational days (GDs) 9 to 20, the pregnant rats were intragastrically administrated caffeine or same volume of saline once per day. According to the dose conversion between human and rat (human:rat 1:6.17 by body surface area comparisons) (Reagan-Shaw et al. 2008), the dosage of the $\mathrm{PCE}(\mathrm{L})$ group corresponds to the daily human $(60 \mathrm{~kg})$ consumption of $292 \mathrm{mg}$ caffeine and can be achieved in daily consumption.

On GD20, 36 rat dams from the control, PCE(L) and $\mathrm{PCE}(\mathrm{H})$ groups ( $n=12$ per group) were anesthetized with 3\% isoflurane and killed to extract the male fetuses. The other 24 rat dams from the control and PCE(H) groups
( $n=12$ per group) were allowed to normally deliver for male offspring. The fetal bodyweight was recorded. IUGR was diagnosed when the bodyweight of an animal was two standard deviations less than the mean bodyweight of the control group (Engelbregt et al. 2001). Then, the male fetuses were immediately decapitated to collect blood samples and testes, and the blood samples of the different male fetuses from each litter were pooled as one sample. Fetal testes from each littermate were pooled together and immediately frozen in liquid nitrogen, followed by storage at $-80^{\circ} \mathrm{C}$ for subsequent analyses, and partial fetal right testis was randomly selected and fixed for morphological observation.

Beginning at postnatal day (PD) 1, the pups were weighed weekly until postnatal week (PW) 12. The bodyweight gain rate was calculated as follows (Xu et al. $2012 a)$ : bodyweight gain rate $(\%)=\left(\mathrm{PW}_{\chi}\right.$ bodyweight $\mathrm{PD}_{1}$ bodyweight $\times 100 / \mathrm{PD}_{1}$ bodyweight. At PW10, one male offspring rat was randomly selected from each litter (the chronic stress group, $n=12$ ), and was then exposed to an ice-water $\left(5-7^{\circ} \mathrm{C}\right)$ swim for $5 \mathrm{~min}$ once per day for 2 weeks. At PW12, another male offspring rat was randomly selected to mate with normal females (to avoid inbreeding). The pregnant rats were kept until normal delivery, and the birthweight of the F2 generation was recorded. The animals were anesthetized by isoflurane and euthanized at PW2, PW6 and PW12, respectively. Blood samples were collected, and the serum was isolated. The testes were immediately frozen in liquid nitrogen, followed by storage at $-80^{\circ} \mathrm{C}$ for subsequent analyses, and partial right testis was randomly selected and fixed for morphological observation.

\section{Hormonal level measurements}

The concentrations of serum corticosterone and fetal serum testosterone were measured by ELISA kits, following the manufacturer protocol. Fetal intra-testicular testosterone content was measured using previously described methods (Mylchreest et al. 2002), and the assay had a $40 \mathrm{pg} /$ tissue limit of detection. Adult serum testosterone and intra-testicular testosterone content were measured using radioimmunoassay kits following the manufacturer protocol.

\section{Histological and ultra-microstructure measurements}

As described by Park et al. (2015), immediately after removal, one testis from each animal was processed for sectioning. Serial sections of $5 \mu \mathrm{m}$ thickness were 
taken from the mid portion of each testis and stained with hematoxylin-eosin (HE). All histomorphometric evaluations were performed by the same trained, calibrated, and blinded examiner using an image analysis system (Olympus) coupled to an Olympus AH-2 light microscope (Olympus). Four serial sections were traced for fetal right testis per animal $(n=3)$, and then diameter and area of fetal testis were measured to obtain a mean value per animal at 100× magnification.

The fetal testis was dehydrated through a graded series of ethanol and embedded in Epon 812. Ultrathin sections $(\sim 50 \mathrm{~nm})$ were cut with LKB-V ultramicrotome (Bromma, Sweden), dually stained with uranyl acetate and lead citrate, and examined with a Hitachi H600 transmission electron microscope (TEM) (Hitachi). Digital images were acquired directly by a computer (Dell).

\section{Sperm count, motility and morphology examinations}

Samples were obtained from the right caudal epididymides of the rats at PW12 for the sperm count and motility analysis as previously described (Toure et al. 2007). The caudal epididymides were cut into pieces in phosphatebuffered saline (PBS, pH 7.4, $37^{\circ} \mathrm{C}$ ). The sperm released into the PBS were then incubated for $15-30 \mathrm{~min}$ at $37^{\circ} \mathrm{C}$ in $5 \% \mathrm{CO}_{2}$ to allow sperm diffusion. $10 \mu \mathrm{L}$ of sperm suspension was placed on a preheated $\left(37^{\circ} \mathrm{C}\right)$ slide, covered with a cover slip and immediately examined using a light microscope at 100x. The sperm count was determined with a hemocytometer and expressed as $\times 10^{6}$ cells $/ \mathrm{mL}$. Another part of the suspension was drawn by capillary action into a prewarmed $\left(37^{\circ} \mathrm{C}\right)$ chamber slide for the quantitative assessment of motility using a HamiltonThorne motility analyzer (Hamilton-Thorne Biosciences, Beverly, MA, USA).

Sperm samples were obtained from the cauda of the left epididymis for morphology examinations. Samples of $2 \mu \mathrm{L}$ of the epididymal fluid were homogenized in $2 \mathrm{~mL}$ of bidistilled water. One drop of the solution was smeared onto a glass slide and air-dried. The smears were stained with HE. For the morphological evaluation, 200 spermatozoa were randomly analyzed, and the percentage of abnormal spermatozoa was obtained. Morphological abnormalities consisting of the head and tail of the spermatozoa were classified according to the modified descriptions and were adapted for the experimental model used.

\section{Immunohistochemistry and immunofluorescence measurements}

Testes were fixed overnight in 4\% paraformaldehyde fixative and embedded in paraffin. For immunological histological chemistry (IHC) analysis, the sections were incubated overnight at $4^{\circ} \mathrm{C}$ with the following antibodies: anti-Ki67 (1:1000), anti-IGF1 (1:500) and anti-HSD3B (1:500). Immunohistochemical analysis was performed using a DAB staining kit to determine the expressional levels of Ki67, HSD3B and IGF1 proteins in the testes. Immunostaining for the negative control was performed on parallel sections, in which the primary antibody was replaced with non-immune rabbit IgG. The intensity of staining was determined by measuring the mean optical density in five random fields for each section. For immunofluorescence (IF) analysis, primary antibody was diluted as optimized (HSD3B 1:100) and was incubated overnight at $4^{\circ} \mathrm{C}$. After rewarming for $15 \mathrm{~min}$, the corresponding fluorescent secondary antibody (1:400) were added, then incubated at room temperature for $1 \mathrm{~h}$ in the dark. Nuclear counterstain (DAPI; Sigma-Aldrich) was diluted 1:500 in Tris-buffered saline (TBS) and incubated for $10 \mathrm{~min}$. As described previously (Motohashi et al. 2016), the number of LCs per unit square of interstitial tissue areas $\left(10^{4} \mu \mathrm{m}^{2}\right)$ were calculated by examining 25 randomly selected sites in each group to avoid a sampling bias. All images were captured using an Olympus AH-2 light microscope (Olympus). Analysis of the stained images was performed using Olympus software.

\section{Leydig cell culture}

Mouse Leydig TM3 cells were grown and maintained in Dulbecco Modified Eagle Medium (DMEM) supplemented with $10 \%$ fetal bovine serum and $1 \%$ penicillin/streptomycin. The TM3 cells liberated during digestion were collected and plated at a density of $4 \times 10^{5}$ cells per well in six-well plates in medium. The cells were treated with various concentrations of caffeine $(1,10$ and $100 \mu \mathrm{M})$ or corticosterone $(250,750$ and $1250 \mathrm{nM})$ for 3 days, and then harvested for further analysis. To confirm that the effect of corticosterone on TM3 cells was mediated by increased glucocorticoid receptor (GR) and decreased IGF1, $2.5 \mu \mathrm{M}$ RU486 or $100 \mathrm{ng} / \mathrm{mL}$ IGF1 were used alone or combined with $1250 \mathrm{nM}$ corticosterone. (c) 2019 Society for Endocrinology Published by Bioscientifica Ltd.
Printed in Great Britain 


\section{Total RNA extraction, reverse transcription and RT-qPCR}

Total RNA was isolated from testicular tissue and TM-3 cells using TRIzol Reagent following the manufacturer's protocol. After isolation, the quality of the RNA samples was assessed using a NanoDrop spectrophotometer and 2-3\% agarose gel (Rivera-Torres 2015). For each RNA sample, $1 \mu \mathrm{g}$ of RNA was used for cDNA synthesis. First, genomic DNA contamination was removed by incubating the RNA with dsDNase at $37^{\circ} \mathrm{C}$ for $2 \mathrm{~min}$. After heat inactivation, we proceeded to cDNA synthesis by incubating the RNA with $1 \mu \mathrm{L}$ of oligo(dT) ${ }_{18}$ primer $(100 \mathrm{pM}), 0.5 \mathrm{mM}$ of dNTP Mix, $4 \mu \mathrm{L}$ of $5 \times$ RT Buffer, $1 \mu \mathrm{L}$ of Maxima H Minus Enzyme Mix and $3 \mu \mathrm{L}$ of nuclease-free water at $50^{\circ} \mathrm{C}$ for $30 \mathrm{~min}$ followed by $5 \mathrm{~min}$ at $85^{\circ} \mathrm{C}$. The controls for each reaction were the RNA sample without reverse transcriptase (RNA-RT) and no RNA with reverse transcriptase (no RNA+RT). RT-qPCR was performed using the ABI StepOne RT-PCR thermal cycler (Thermo Fisher Scientific) in a $10 \mu \mathrm{L}$ reaction mixture. The reaction mixture contained $5.6 \mu \mathrm{L}$ of oligo mix $(0.5 \times$ Power SYBR Green PCR Master Mix and $50-100 \mathrm{nM}$ of forward and reverse primers) and $4.4 \mu \mathrm{L}$ of diluted cDNA (1-10 ng). The cycling conditions were as follows: $2 \mathrm{~min}$ at $50^{\circ} \mathrm{C}$, followed by $10 \mathrm{~min}$ at $95^{\circ} \mathrm{C}$ for polymerase activation and then 40 cycles of $95^{\circ} \mathrm{C}$ for $15 \mathrm{~s}$ and $60^{\circ} \mathrm{C}$ for $1 \mathrm{~min}$ for primer annealing and extension. To quantify the gene transcripts more precisely, the mRNA level of the housekeeping gene glyceraldehyde 3-phosphatedehydrogenase (Gapdh) was measured and used as a quantitative control. The optimal primer was determined by a separate set of experiments to ensure that both the target gene and Gapdh were amplified with equal efficiency. Each sample was normalized against the Gapdh mRNA content. The sequences for each set of primers are shown in Supplementary Table 2.

\section{Western blot analysis}

Specimens were homogenized in $50 \mathrm{mM}$ Tris- $\mathrm{HCl}$, $150 \mathrm{mM} \mathrm{KCl}(\mathrm{pH} 7.4), 1 \%$ Triton $\mathrm{X}-100$ and $0.25 \mathrm{mM}$ phenylmethylsulfonyl fluoride and centrifuged at $80,000 \mathrm{~g}\left(30 \mathrm{~min}, 4^{\circ} \mathrm{C}\right)$. The pellet was lysed with lysis buffer (10 nM Tris- $\mathrm{HCl}, 1 \%$ sodium dodecyl sulfate (SDS), $1.0 \mathrm{mM}$ ethylene diamine tetraacetic acid, $10 \%$ glycerol and 5\% 2-mercaptoethanol) The protein concentrations in lysates $(4 \mu \mathrm{L})$ were quantified using a Protein 200 Labchip kit (Agilent Technologies Inc.) and run on an Agilent 2100 Bioanalyzer (Agilent Technologies Inc.). An equal amount of protein $(10 \mathrm{~g})$ from each lysate was resolved on 10\% SDS polyacrylamide gels under denaturing conditions and then transferred to Immuno-Blot PVDFs (Bio-Rad). After $1 \mathrm{~h}$ of blocking by immersion in 5\% nonfat dried milk in TBS with $0.1 \%(\mathrm{v} / \mathrm{v})$ Tween 20 (TBST), Western blot analyses were performed using antibodies to IGF1 (diluted 1:500), HSD3B (diluted 1:500) and $\beta$-actin (diluted 1:4000) and incubated overnight at $4^{\circ} \mathrm{C}$ in an orbital shaker. After washing three times with TBST, the membranes were incubated with a 1:2000 dilution of secondary antibodies for $1 \mathrm{~h}$. Finally, the membranes were detected using the ECL Plus Western Blotting Detection System (Applied Biosystems). To verify the relative amounts of protein in each lane, the level of $\beta$-actin was determined as an internal control.

\section{Chromatin immunoprecipitation-polymerase chain reaction (ChIP-PCR)}

The homogenate of testicular tissues was fixed with $1 \%$ formaldehyde for $15 \mathrm{~min}$ at $37^{\circ} \mathrm{C}$ to cross-link DNA and its associated proteins. Glycine ( $0.125 \mathrm{M}$ final concentration) was added to terminate the reaction for $8 \mathrm{~min}$. The lysates were then sonicated to shear the DNA to a size of 200-800 bp. After sonication, the samples were collected by centrifugation and diluted with dilution buffer. After mixing, $10 \mu \mathrm{L}$ of the supernatant was saved as input DNA for normalization of chromatin input. The remainder was divided into $200 \mu \mathrm{L}$ per Eppendorf tube and incubated overnight at $4^{\circ} \mathrm{C}$ on nutator/rocker with specific antibody for H3K9ac (1:50 dilution), H3K14ac (1:50 dilution) or IgG (1:50 dilution) and BSA-treated Protein $\mathrm{G}$ beads to reduce nonspecific background binding. The immunoprecipitated DNA-protein complex was collected by centrifugation and washed sequentially with low-salt, high-salt, LiCl immune complex and Tris-EDTA washing buffer. Prepared elution buffer (1\% SDS, $0.1 \mathrm{M} \mathrm{NaHCO}_{3}$ ) was used to elute the DNA-protein complex. Samples were incubated overnight at $65^{\circ} \mathrm{C}$ with $200 \mu \mathrm{g} / \mathrm{mL}$ proteinase $\mathrm{K}$, and subsequently were purified using a DNA purification kit, following the manufacturer protocol. Purified DNA was dissolved in $100 \mu \mathrm{L}$ of elution buffer finally.

\section{Statistical analysis}

SPSS 13.0 (SPSS Science Inc.) and Prism (GraphPad Software) were used for data analysis. The IUGR rate and bodyweight gain rate were calculated and then transformed by arcsine square-root prior to $t$-test evaluations (Engelbregt et al. 2001, Luo et al. 2014). A paired $t$-test was used to compare the mean values of the groups without chronic stress 
and after chronic stress. Student's t-test and one-way ANOVA followed by a post hoc Dunnett $t$-test or a post hoc Bonferroni $t$-test were performed as appropriate. Statistical significance was defined as $P<0.05$.

\section{Results}

\section{PCE inhibited testis development in male fetal rats}

The results showed that the PCE $(\mathrm{H})$ group had a reduced bodyweight (89.3\% of the control) and increased IUGR rate $(P<0.01$, Fig. $1 \mathrm{~A})$, but it did not differ between the control and PCE(L) groups (Fig. 1A). Meanwhile, the fetal testicular maximum area and maximum diameter of the $\mathrm{PCE}(\mathrm{L})$ and $\mathrm{PCE}(\mathrm{H})$ groups were decreased $(P<0.01$, Fig. 1B). No remarkable disorganized cell arrangement or morphological changes were observed by HE staining (Fig. 1C). However, the immunohistochemical analyses showed that testicular Ki67 protein expression in the $\mathrm{PCE}(\mathrm{H})$ group was decreased $(P<0.05$, Fig. 1D). In addition, the TEM images showed some mitochondrial vacuolation in the testicular LCs of the $\mathrm{PCE}(\mathrm{H})$ group, whereas the PCE(L) group had no such changes (Fig. 1E). These findings suggested that PCE can induce testicular dysplasia in male fetal rats.

\section{PCE changed testosterone synthetic function in male fetal rats}

As shown in Fig. 2, the serum testosterone concentration and intra-testicular testosterone content in the PCE $(\mathrm{H})$ group were markedly lower than their respective controls
A

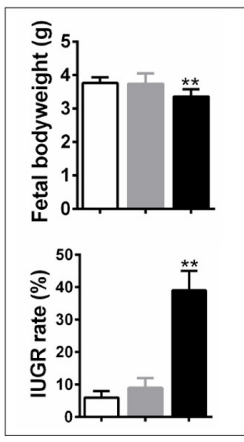

C
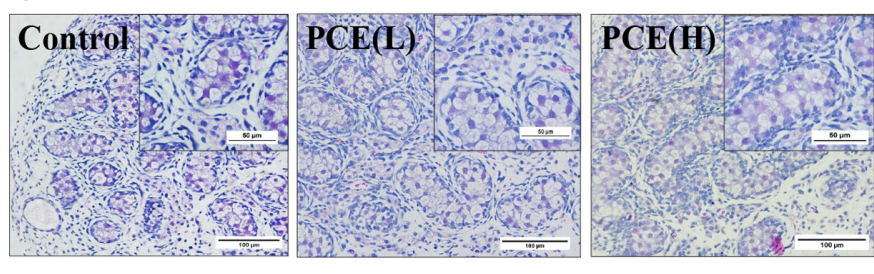

D
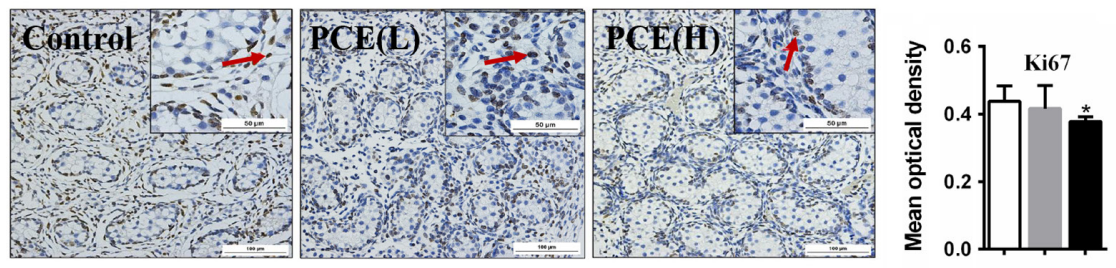

E
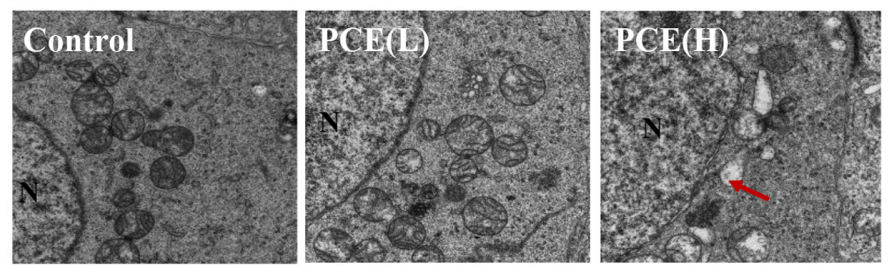

\section{Figure 1}

Effects of prenatal caffeine exposure (PCE) on testicular morphology in male fetal rats. Pregnant rats were intragastrically administered with low-dose (30 mg/kg/day) and high-dose (120 mg/ $\mathrm{kg} /$ day) caffeine once per day from gestational day (GD) 9 to 20, which were assigned to PCE(L) and PCE $(\mathrm{H})$ groups, respectively. At GD20, the fetal rats were taken out. The bodyweight, intrauterine growth retardation (IUGR) rate, testicular diameter and area of male fetal rats were recorded ( $A, n=12)(B, n=3,100 \times)$. The testicular morphology was observed by hematoxylin-eosin dying (C, 200x, 400×), and Ki67 protein expression (red arrows) was detected by immunohistochemistry ( $D, n=3,200 \times, 400 \times)$. The Leydig cells structure (red arrows represent injured mitochondria) was observed by transmission electron microscopy ( $E, 5000 \times)$. Mean \pm S.D., ${ }^{*} P<0.05, * \star P<0.01$ vs control by one-way ANOVA. A full colour version of this figure is available at https://doi.org/10.1530/ JOE-18-0684. https://joe.bioscientifica.com https://doi.org/10.1530/JOE-18-0684 (c) 2019 Society for Endocrinology Published by Bioscientifica Ltd.
Printed in Great Britain 

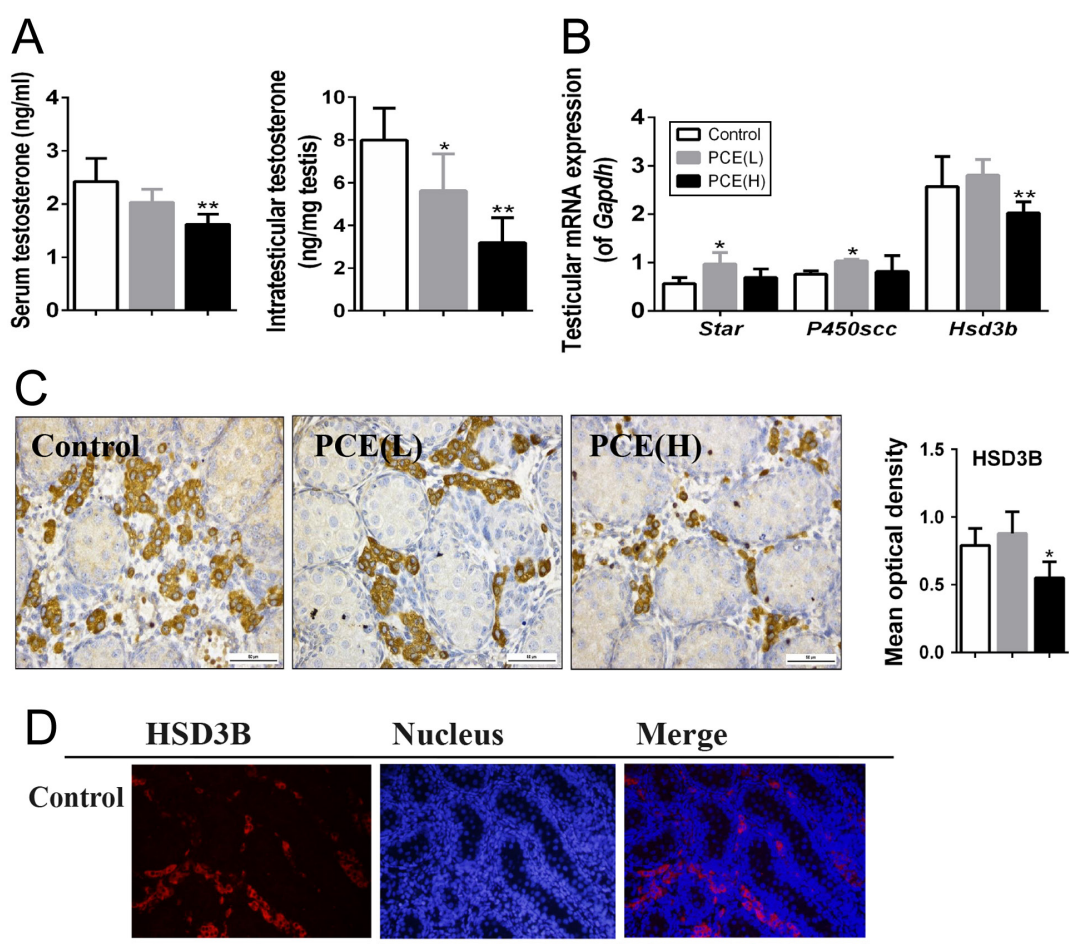

Merge
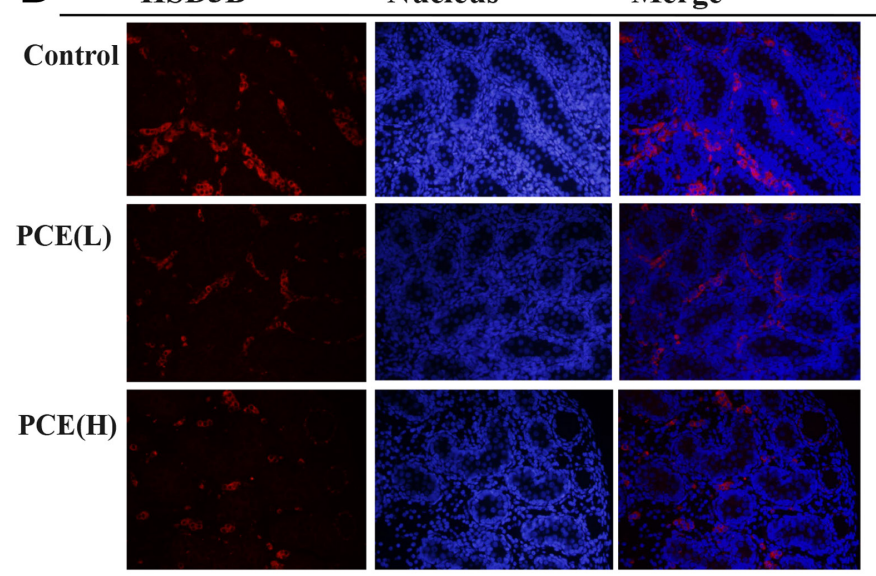

(1)

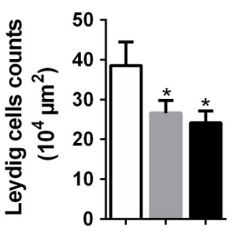

\section{Figure 2}

Effects of prenatal caffeine exposure (PCE) on testicular steroidogenesis in male fetal rats. Pregnant rats were intragastrically administered with low-dose $(30 \mathrm{mg} / \mathrm{kg} /$ day) and high-dose $(120 \mathrm{mg} / \mathrm{kg} /$ day) caffeine once per day from gestational day (GD) 9 to 20, which were assigned to $P C E(L)$ and $P C E(H)$ groups, respectively. At GD20, the fetal rats were taken out. Serum testosterone concentration and intra-testicular testosterone content were measured by ELISA ( $\mathrm{A}$, $n=8-12$ ). The mRNA expression of steroidogenic acute regulatory protein (Star), cytochrome P450 cholesterol side chain cleavage (P450scC) and $3 \beta$-hydroxysteroid dehydrogenase $(H s d 3 b)$ were detected by RT-qPCR (B, $n=8-12)$. HSD3B protein level was detected by immunohistochemistry ( $C$, $n=3,400 \times$ ). Leydig cells (stained with HSD3B, a cytoplasmic steroidogenic enzyme marker) counts were detected by immunofluorescence staining $(\mathrm{D}, n=3,200 \times)$. Mean \pm S.D., $* P<0.05, * * P<0.01$ vs control by one-way ANOVA. A full colour version of this figure is available at https://doi. org/10.1530/JOE-18-0684.

$(P<0.01$, Fig. 1A), as well as the mRNA and protein expressions of HSD3B $(P<0.05, P<0.01$, Fig. $1 \mathrm{~B}$ and $\mathrm{C})$. Although the serum testosterone concentration remained unchanged and the intra-testicular testosterone content decreased $(P<0.05$, Fig. $1 \mathrm{~A})$ in the PCE(L) group, the mRNA expression of steroidogenic acute regulatory protein (Star) and cytochrome $\mathrm{P} 450$ cholesterol side chain cleavage (P450sCC) increased $(P<0.05$, Fig. 1B). The number of LCs $\left(\right.$ HSD3B $\left.^{+}\right)(P<0.05$, Fig. 1D) decreased obviously in both groups. The above results indicated that PCE could alter the testosterone synthetic function in male fetal rats.

\section{PCE-induced postnatal catch-up growth in male offspring rats}

After birth, we recorded the bodyweight and observed the testicular morphology at different time points (PW2, PW6 and PW12) in the PCE(H) groups. The male offspring rats exhibited a lower bodyweight from PW0-1, which gradually increased and was close to the control level at
PW12, whereas the corresponding body weight gain rates were significantly higher $(P<0.01$, Fig. 3A). Meanwhile, the testicular weight, testis index and seminiferous tubule diameter increased gradually in the $\mathrm{PCE}(\mathrm{H})$ group $(P<0.05, P<0.01$, Fig. 3B and $\mathrm{C})$. These results suggested that the IUGR offspring rats in the PCE $(\mathrm{H})$ group exhibited catch-up growth after birth.

\section{PCE-induced testicular dysfunctions in male offspring rats}

We also observed postnatal alterations to testicular function in the male offspring rats. Compared to the control group, the serum testosterone concentration in the $\mathrm{PCE}(\mathrm{H})$ group decreased at PW2 and PW12, whereas there was no change at PW6 $(P<0.01$, Fig. 4A). Meanwhile, the intra-testicular testosterone content continued to be lower than that of the control groups $(P<0.05, P<0.01$, Fig. $4 \mathrm{~A})$, as well as the HSD3B expression $(P<0.05$, Fig. $4 \mathrm{~B}$ and $\mathrm{C})$. Moreover, the number of LCs and the amount of spermatozoon in 
A
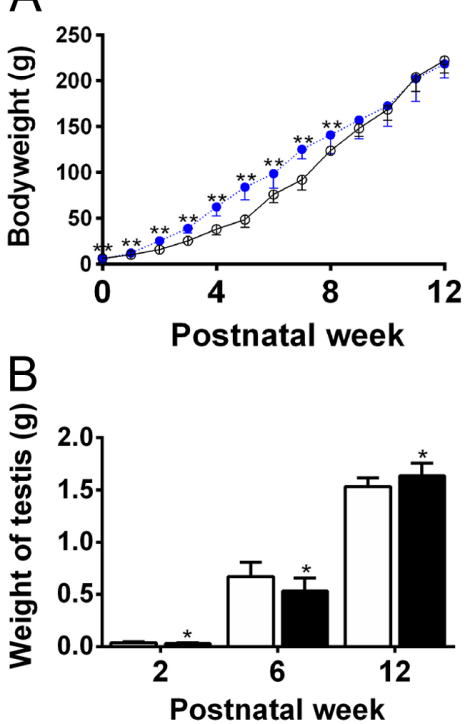
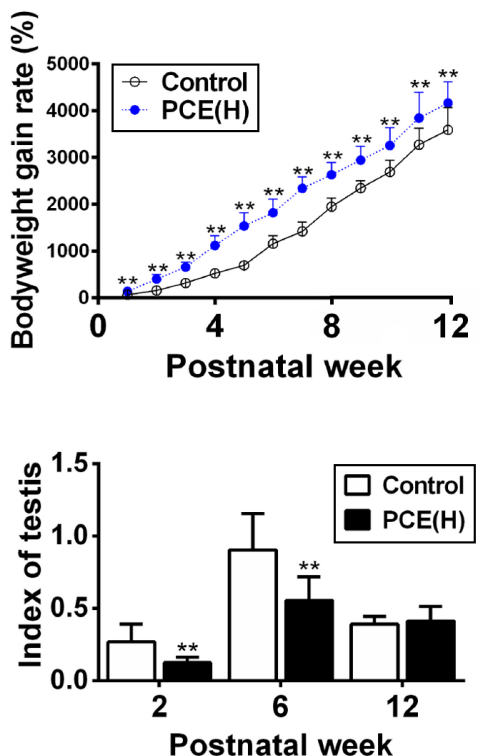

C

\section{Control $\quad$ PCE $(\mathrm{H})$}
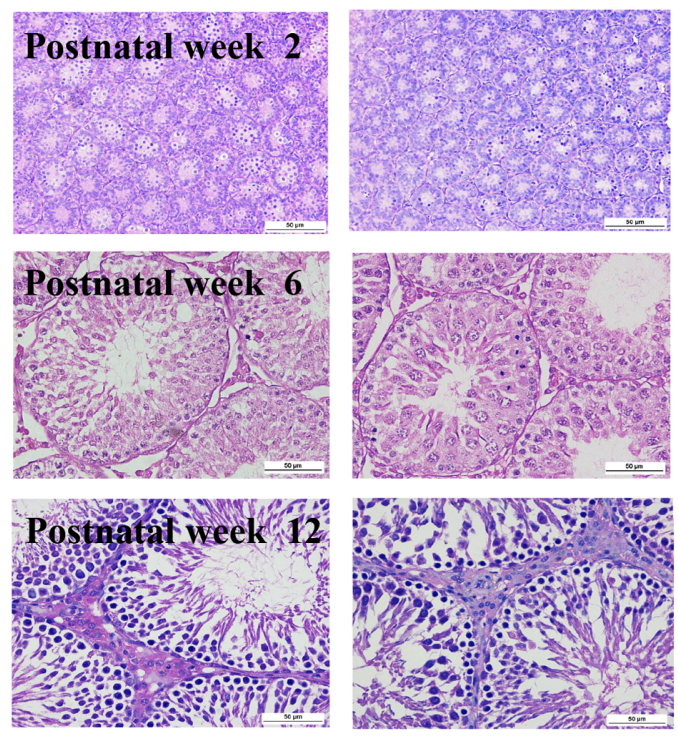

\section{Figure 3}

Effects of prenatal caffeine exposure (PCE) on testicular morphology in male offspring rats after birth. Pregnant rats in the PCE $(\mathrm{H})$ group were allowed to deliver spontaneously at term. Bodyweight/bodyweight gain rate, testis weight/ index and seminiferous tubule diameter/ epithelium thickness were recorded and calculated at different time points after birth $(A, B$, $n=8-12)(C, n=3,400 \times)$. Mean \pm S.D., $* P<0.05$, $\star \star P<0.01$ vs control by the Student's $t$-test. A full colour version of this figure is available at https:// doi.org/10.1530/JOE-18-0684. the PCE(H) group were lower at PW12 $(P<0.05, P<0.01$, Fig. $4 \mathrm{D}$ and $\mathrm{E})$. However, there was no difference in sperm motility between the control and PCE(H) groups (Fig. 4E). Male offspring rats were mated with normal female rats at PW12 to produce F2 generation. The pregnancy rate of the normal female rats remained unchanged, whereas naturally born F2-generation male rats had a decreased birth weight $(87.1 \%$ of the control) $(P<0.05$, Fig. 4F). In addition, a significantly higher frequency of morphologically abnormal spermatozoa was noted in the PCE $(\mathrm{H})$ group $(P<0.05$, Fig. 4G). Collectively, these results indicated that PCE induced low steroidogenesis and abnormal spermatogenesis in the male offspring rats.

\section{PCE-induced changes of serum corticosterone concentration and testicular IGF1 expression before and after birth}

We further investigated the serum corticosterone concentration and the expression of testicular IGF1 at different time points (GD20, PW2, PW6 and PW12). In utero, the serum corticosterone concentration and testicular $G r$ expression were higher $(P<0.05, P<0.01$, Fig. 5A and $\mathrm{B})$ but the IGF1 expression was lower in response to $\mathrm{PCE}(\mathrm{H})(P<0.05$, Fig. 5C and D). The H3K14ac level in the $I g f 1$ promoter region was also decreased $(P<0.01$, Fig. 5E). However, these indexes did not change 
A

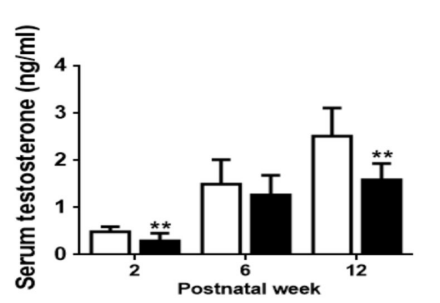

B

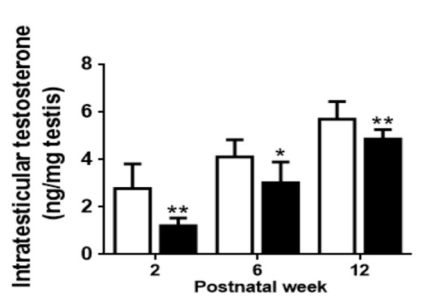

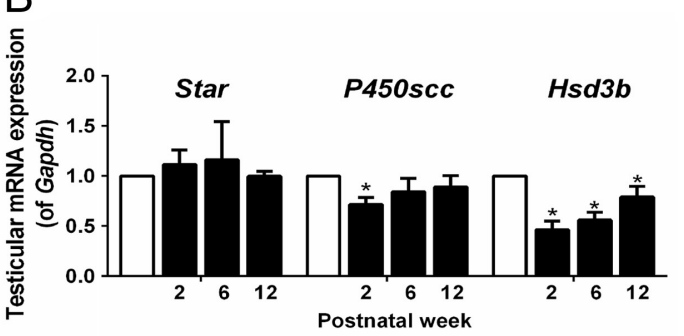

C
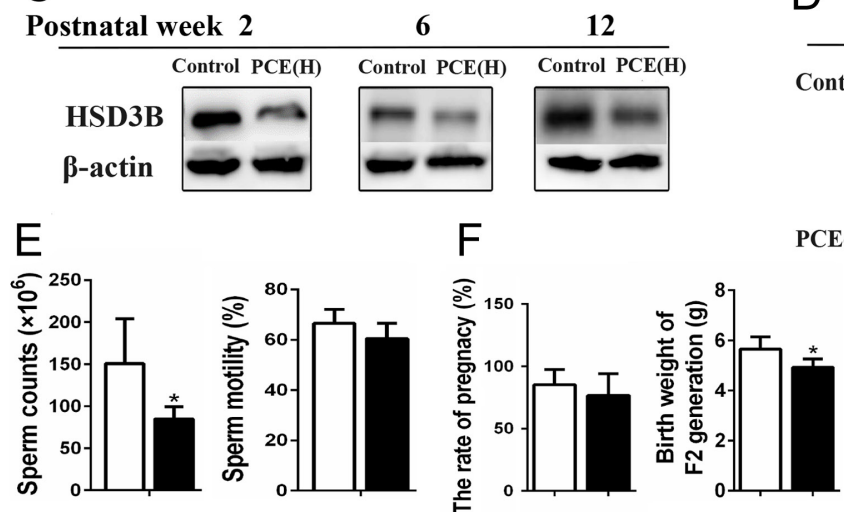

D

G
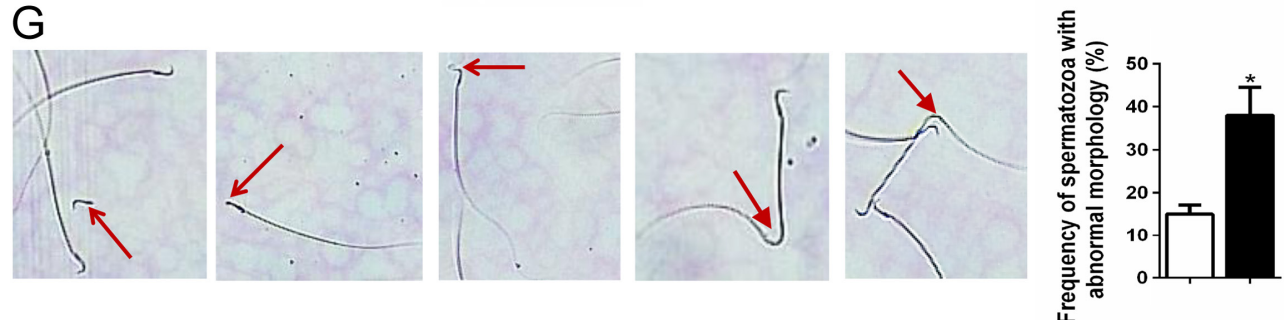

\section{Figure 4}

Effects of prenatal caffeine exposure (PCE) on testicular function in male offspring rats after birth. Pregnant rats in the PCE(H) group were allowed to deliver spontaneously at term. Serum testosterone concentration and intra-testicular testosterone content were measured by radioimmunoassay $(\mathrm{A}, n=8-12)$. The mRNA expression of steroidogenic acute regulatory protein (Star), cytochrome P450 cholesterol side chain cleavage (P450scC) and $3 \beta$-hydroxysteroid dehydrogenase $(H s d 3 b)$ were detected by RT-qPCR (B, $n=8-12)$. HSD3B protein level was detected by Western blot (C, $n=3)$. Leydig cells (stained with HSD3B, a cytoplasmic steroidogenic enzyme marker) counts were detected by immunofluorescence staining (D, $n=3,400 \times$ ). Sperm counts and sperm motility were measured $(\mathrm{E}, n=5)$. The rate of pregnancy and bodyweight of $\mathrm{F} 2$ generation male rats were recorded $(\mathrm{F}, n=8-12)$. Representative photomicrographs of sperm smear collected from epididymal cauda in PCE(H) group were shown (head abnormalities (thin arrows) and tail abnormalities (thick arrows)) (G). The frequency of spermatozoa with abnormal morphology was observed (G, $n=5$ ). Mean \pm S.D., $\star P<0.05, \star \star P<0.01$ vs control by the Student's $t$-test. A full colour version of this figure is available at https://doi.org/10.1530/JOE-18-0684.

in the PCE(L) group (Fig. 5A, B, C, D and E). After birth, the serum corticosterone concentration showed a decreasing trend over time and was particularly significantly reduced at PW12 $(P<0.05, P<0.01$, Fig. 5F). Conversely, testicular IGF1 expression, whether at mRNA or protein levels, increased gradually from PW2-12 ( $P<0.01$, Fig. 5G and $\mathrm{H})$. We then found that the H3K14ac level of Igf1 was reduced at PW2, but displayed no noticeable changes after that $(P<0.05$, Fig. 5I). Taken together, these findings suggested that high serum glucocorticoid level can negatively regulate testicular IGF1 expression.

\section{Effects of chronic stress on serum corticosterone level, testicular IGF1 expression and steroidogenesis}

To gain further insight into the negative regulation of serum corticosterone on testicular IGF1 expression and steroidogenesis, we treated male offspring rats with 2 weeks of chronic stress to increase their serum corticosterone level. We then examined the testicular IGF1 expression and steroidogenesis-related indices with or without stress. With chronic stress, both the control and PCE(H) groups showed elevated serum corticosterone concentrations 

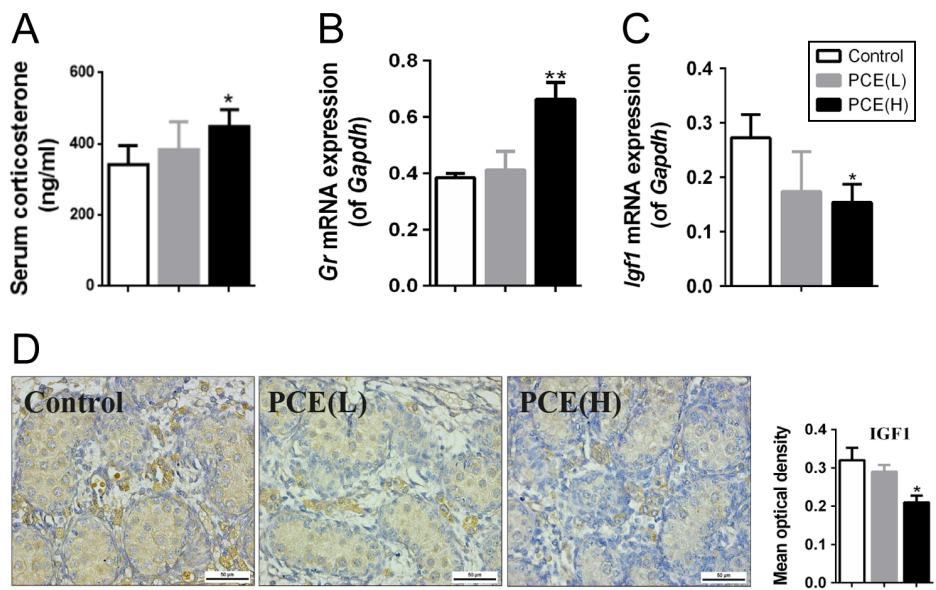
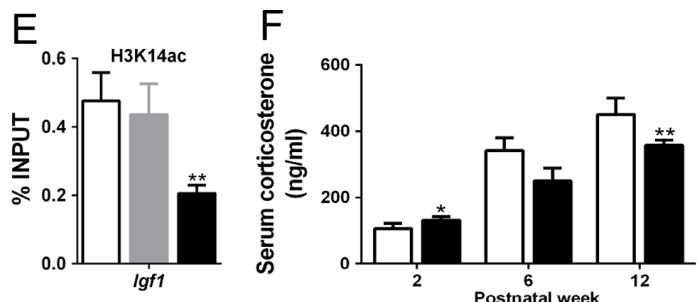

$\mathrm{H}$

Postnatal week 2

6

12

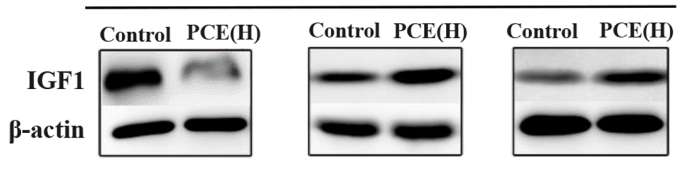

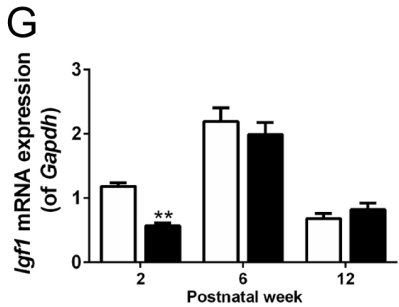

I

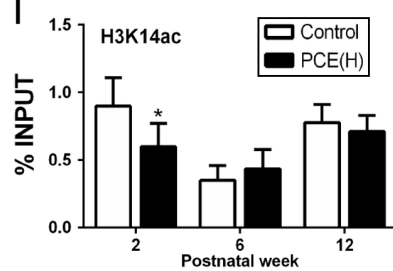

Figure 5

Effects of prenatal caffeine exposure (PCE) on corticosterone concentration and insulin-growth factor 1 (IGF1) expression in male offspring rats before and after birth. Pregnant rats were intragastrically administered with low-dose (30 mg/kg/day) and high-dose (120 mg/kg/day) caffeine once per day from gestational day (GD) 9 to 20 , which were assigned to PCE $(\mathrm{L})$ and $P C E(H)$ groups, respectively. And pregnant rats in the $\mathrm{PCE}(\mathrm{H})$ group were allowed to deliver spontaneously at term. Serum corticosterone concentration was measured by ELISA (A, F, $n=8-12)$. The mRNA expression of glucocorticoid receptor $(G r)$ and Igf1 were detected by RT-qPCR (B, C, G, $n=8-12$ ). The levels of histone 3 lysine 14 acetylation (H3K14ac) in the Igf1 promoter were measured by ChIP-PCR (E, I, $n=3)$. IGF1 protein level was detected by immunohistochemistry $(D$, $n=3,400 \times)$ or Western blot $(H, n=3)$. Mean \pm S.D. $\star p<0.05, * * P<0.01$ vs control by one-way ANOVA or Student's $t$-test. A full colour version of this figure is available at https://doi.org/10.1530/ JOE-18-0684. and reduced testicular $I g f 1$ expression $(P<0.05, P<0.01$, Fig. $6 \mathrm{~A}$ and B). Moreover, the level of H3K14ac in the Igf1 promoter was downregulated by chronic stress $(P<0.05$, $P<0.01$, Fig. 6C). The expressions of steroid synthetase Star, P450scc, and Hsd3b decreased, as did the serum testosterone and intra-testicular testosterone levels $(P<0.05, P<0.01$, Fig. 6D, E and F). These data indicated that a high glucocorticoid level could negatively alter the H3K14ac and expression levels of IGF1, which further inhibited the testicular steroidogenesis.

\section{Corticosterone (rather than caffeine) inhibited IGF1 expression and steroidogenesis in TM3 cells}

We employed TM3 cells, which are a type of LCs, to investigate the effects of caffeine and corticosterone on steroidogenesis. Based on the fetal serum caffeine concentration $(155 \pm 28 \mu \mathrm{M}$, Wang et al. 2014) and the aforementioned fetal serum corticosterone concentration (Fig. 5A), we treated the TM3 cells with different concentrations of caffeine $(1,10$ and $100 \mu \mathrm{M})$ and corticosterone (250, 750 and $1250 \mathrm{nM})$.
No cytotoxicity was observed up to $100 \mu \mathrm{M}$ caffeine or $1250 \mathrm{nM}$ corticosterone treatment for 3 days (data not shown). Under the caffeine treatment, there was no obvious change in the expression of $I g f 1$ and $H s d 3 b$ (Fig. 7A and B), but the expression of Star and P450scc increased $(P<0.01$, Fig. $7 \mathrm{~B})$, as well as the testosterone concentration in the cell culture supernatant $(P<0.05$, $P<0.01$, Fig. 7C). Conversely, these indicators were inhibited following corticosterone treatment $(P<0.05$, $P<0.01$, Fig. 7D, E and F), as was the level of H3K14ac in the Igf1 promoter region $(P<0.01$, Fig. $7 \mathrm{~J})$. These results indicated that caffeine enhanced steroidogenesis, whereas corticosterone inhibited steroidogenesis in the TM3 cells. To further confirm the effect of corticosterone and IGF1 in steroidogenesis, we administered $2.5 \mu \mathrm{M}$ RU486 (a GR inhibitor) or $100 \mathrm{ng} / \mathrm{mL}$ IGF1 to treat the TM3 cells. The expressions of steroid synthetase and testosterone production were significantly reversed $(P<0.05, P<0.01$, Fig. 7G and $\mathrm{H}$ ). Moreover, the expression and H3K14ac level of $I g f 1$ were also upregulated after RU486 treatment $(P<0.01$, Fig. $7 \mathrm{I}$ and $\mathrm{J})$. These results indicated that corticosterone (rather than caffeine) downregulated the 

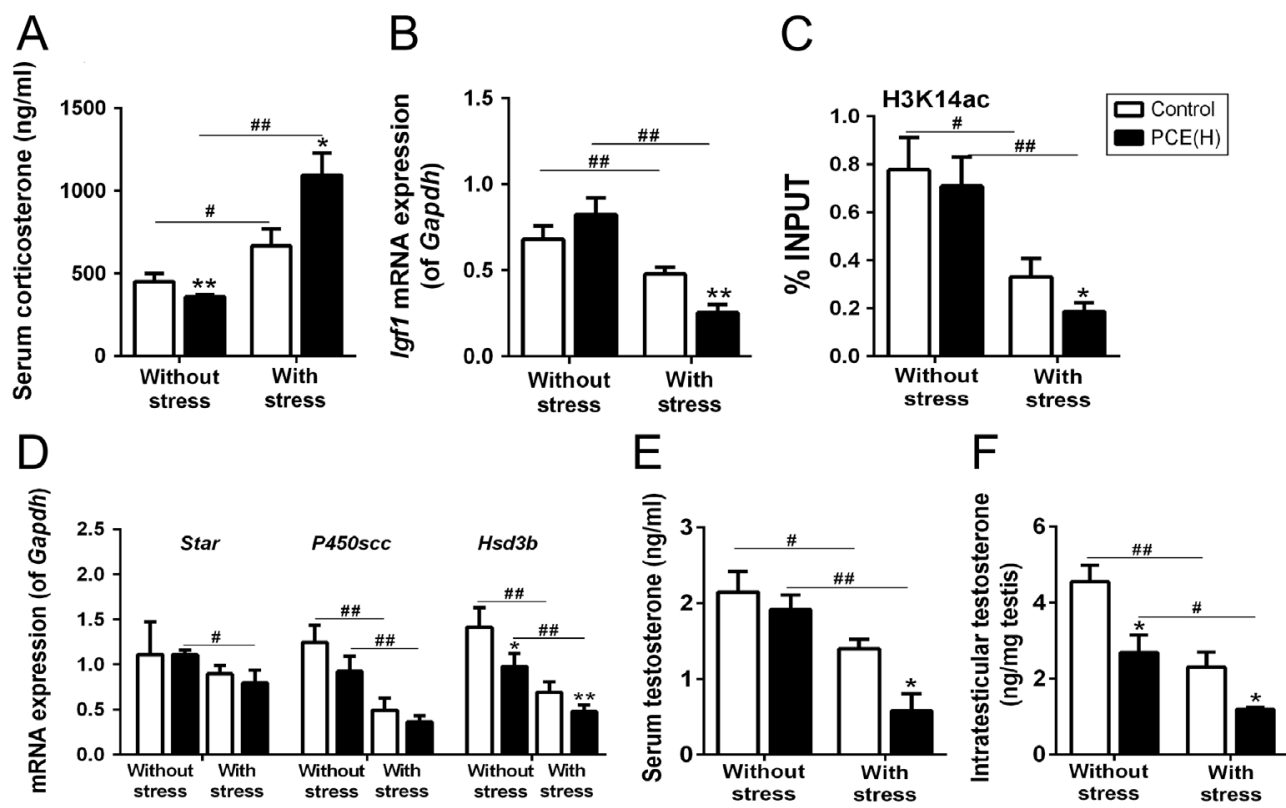

\section{Figure 6}

Effects of chronic stress on testicular insulin-growth factor 1 (IGF1) expression and steroidogenesis in male offspring rats followed prenatal caffeine exposure (PCE). Pregnant rats in the $\mathrm{PCE}(\mathrm{H})$ group were allowed to deliver spontaneously at term. Male pups were randomly selected from each dam and subjected to two weeks chronic stress or not from postnatal week 10 to 12. Serum corticosterone concentration was measured by ELISA (A, $n=8-12)$. The mRNA expression of Igf1, steroidogenic acute regulatory protein (Star), cytochrome P450 cholesterol side chain cleavage (P450scc) and 3ß-hydroxysteroid dehydrogenase (Hsd3b) were detected by RT-qPCR (B, D, $n=8-12$ ). The levels of histone 3 lysine 14 acetylation (H3K14ac) in the Igf1 promoter were measured by ChIP-PCR $(C, n=3)$. Serum testosterone concentration and intra-testicular testosterone content were measured by radioimmunoassay $(E$, $F$, $n=8$-12). Mean \pm S.D., ${ }^{*} P<0.05$, ${ }^{*} P P<0.01$ vs control by independent t-test; $\# P<0.05,{ }^{*} \# P<0.01$ vs no stress by paired $t$-test.

H3K14ac level and expression of IGF1 via GR, which further inhibited steroidogenesis in the LCs.

\section{Discussion}

\section{Altered IGF1 expression by PCE may contribute to testicular dysplasia and dysfunction}

Testicular development has been depreciated because of maternal undernutrition, changes in lifestyle and exposure to xenobiotics during pregnancy (Dupont et al. 2012). The fetal androgen (testosterone) level is known to be a major determinant of male reproductive disorders (Welsh et al. 2008, 2010) and can be affected by maternal caffeine consumption (Ramlau-Hansen et al. 2008, Dorostghoal et al. 2012, Cavalcante et al. 2014). Previous studies have suggested that IGF1 could influence LC development and testosterone-related steroid synthase expression. In Igf1-knockout mice, the differentiation of LCs and the expression of steroid synthetase were inhibited, as was the level of circulating testosterone (Wang \& Hardy 2004, Hu et al. 2010). However, the data still appear to be strikingly absent concerning whether PCE could reduce IGF1 expression and thus influence testicular development during the intrauterine period. Therefore, we detected the expression of local IGF1 in testis tissue and found that it was lower in the $\operatorname{PCE}(\mathrm{H})$ group at GD20. The fetal testis size and the expression of Ki67 were decreased, accompanied by obvious mitochondrial damage in LCs. Meanwhile, the $\operatorname{PCE}(\mathrm{H})$ group exhibited fewer LCs and lower testosterone production. These results suggest that IGF1 is likely involved in PCE-induced fetal testicular dysplasia.

Studies have shown that low birth weight is one of the risk factors of reproductive disorders in males (Main et al. 2006, Nordenvall et al. 2014). In the present study, the $\operatorname{PCE}(\mathrm{H})$ group displayed a reduced bodyweight and increased IUGR rate at GD20. After the intrauterine period of growth inhibition, body growth often does not merely return to a normal rate; in fact, it exceeds the normal growth rate, resulting in catch-up growth (Hediger et al. 1998). An increasing number of studies have confirmed that individuals with IUGR will undergo catch-up growth after birth, and this growth is mainly associated with elevated IGF1 expression (Kajantie 2003, Jensen et al. 2015). Despite a greater proliferative capacity than normal, 


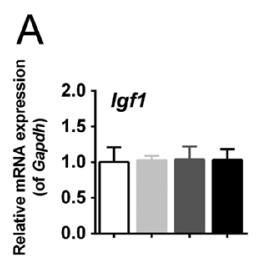

D
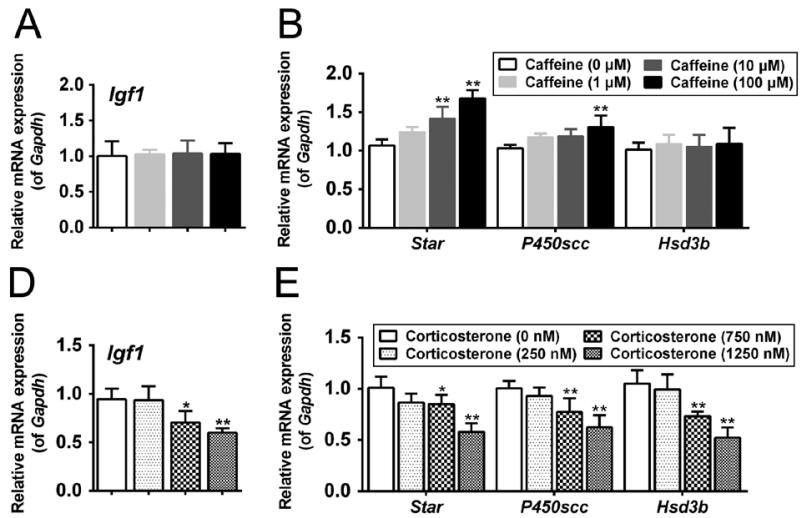

$\mathrm{G}$
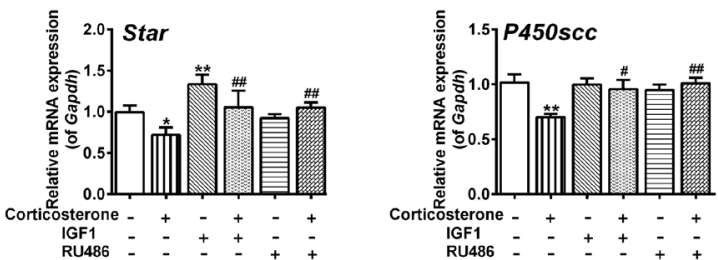

$\mathrm{H}$
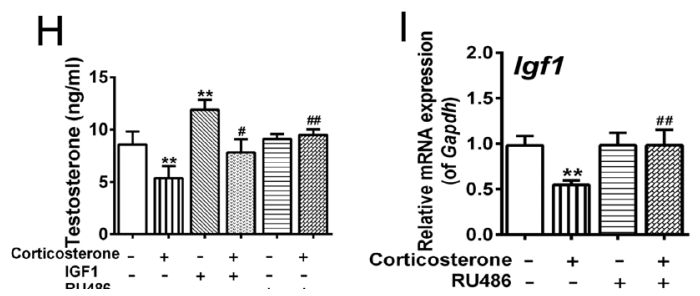

C

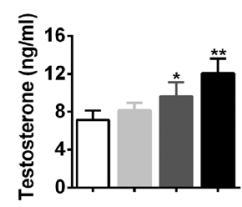

$\mathrm{F}$
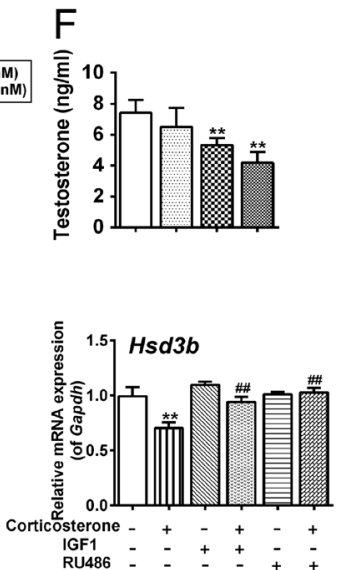

$\mathrm{J}$

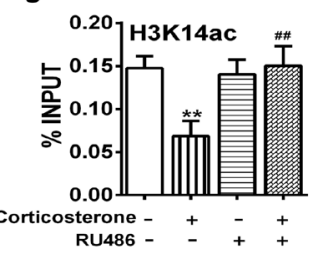

\section{Figure 7}

Direct effects of caffeine and corticosterone on steroidogenesis in mouse Leydig TM3 cells. The TM3 cells were treated with different concentrations of caffeine and corticosterone for 3 days. Above-mentioned treatment of the cells showed no cytotoxicity. Then, TM3 was treated in the presence of corticosterone $(750 \mathrm{nM})$ with insulin-growth factor 1 (IGF1) $(100 \mathrm{ng} / \mathrm{mL})$ or RU486 $(2.5 \mu \mathrm{M})$. The mRNA expression of Igf1, steroidogenic acute regulatory protein (Star), cytochrome P450 cholesterol side-chain cleavage (P450sCC) and 3 $\beta$-hydroxysteroid dehydrogenase $(\mathrm{Hsd} 3 b)$ were determined by RT-qPCR (A, B, D, E, $\mathrm{G}, \mathrm{I}, n=5)$. The testosterone concentration in the cell culture supernatant was detected by radioimmunoassay ( $\mathrm{C}, \mathrm{F}, \mathrm{H}, n=5)$. The levels of histone 3 lysine 14 acetylation (H3K14ac) in the Igf1 promoter were measured by ChIP-PCR (J, $n=3$ ). Mean \pm s.D., $* P<0.05, * * P<0.01$ vs control; $\# P<0.05$, \#\#P<0.01 vs $750 \mathrm{nM}$ corticosterone by one-way ANOVA or Student's $t$-test. tissues of developmental inhibition do not always fully recover to normal during catch-up growth (Finkielstain et al. 2013). In the present study, the weight results suggested that IUGR offspring exhibited a typical catch-up growth pattern. Under this physical condition, we further observed the testicular IGF1 expression and development at different time points (PW2, PW6 and PW12). Our results showed that the testicular weight, testis index and seminiferous tubule diameter of the PCE $(\mathrm{H})$ group increased gradually from PW2-12 and were close to or even higher than those of the control group at PW12. Meanwhile, the testicular IGF1 expression increased relatively with time. Although there were fewer LCs and less steroidogenesis at PW12 than those of their respective controls, there was still a growing trend with HSD3B expression increasing from $46 \%$ (PW2) of the control to 79\% (PW12) of the control and the intra-testicular testosterone content increasing from 43\% (PW2) to 85\% (PW12). Taken together, PCE can induce a series of compensatory effects on testicular development in IUGR offspring after birth, which is associated with increased testicular IGF1 expression.

\section{GC-IGF1 axis programming is involved in testicular dysplasia and dysfunction}

Glucocorticoid is secreted by the adrenal gland and is a regulatory factor of IGF1 expression (Fernandez-Cancio et al. 2008). Previously, we have confirmed that PCE could inhibit the development of the fetal hypothalamicpituitary-adrenal (HPA) axis, which may be associated with fetal overexposure to maternal glucocorticoid ( $\mathrm{Xu}$ et al. $2012 b$ ). This would further lead to low basal activity and an increased sensitivity of the HPA axis in the offspring rats and directly influences the secretion of corticosterone and the susceptibility to multiple diseases (Xu et al. 2012a, 2018). Hence, serum corticosterone level gradually decreased after birth but can be upregulated by chronic stress. Studies have shown that there is a negative correlation between the cortisol in human cord blood and the IGF1 signaling pathway (Cianfarani et al. 1998). In the present study, we discovered a similar phenomenon. Specifically, in utero, the fetal serum corticosterone level increased while the testicular IGF1 expression decreased in the PCE $(\mathrm{H})$ group. However, after birth, the serum corticosterone level https://joe.bioscientifica.com https://doi.org/10.1530/JOE-18-0684 (c) 2019 Society for Endocrinology Published by Bioscientifica Ltd. Printed in Great Britain 


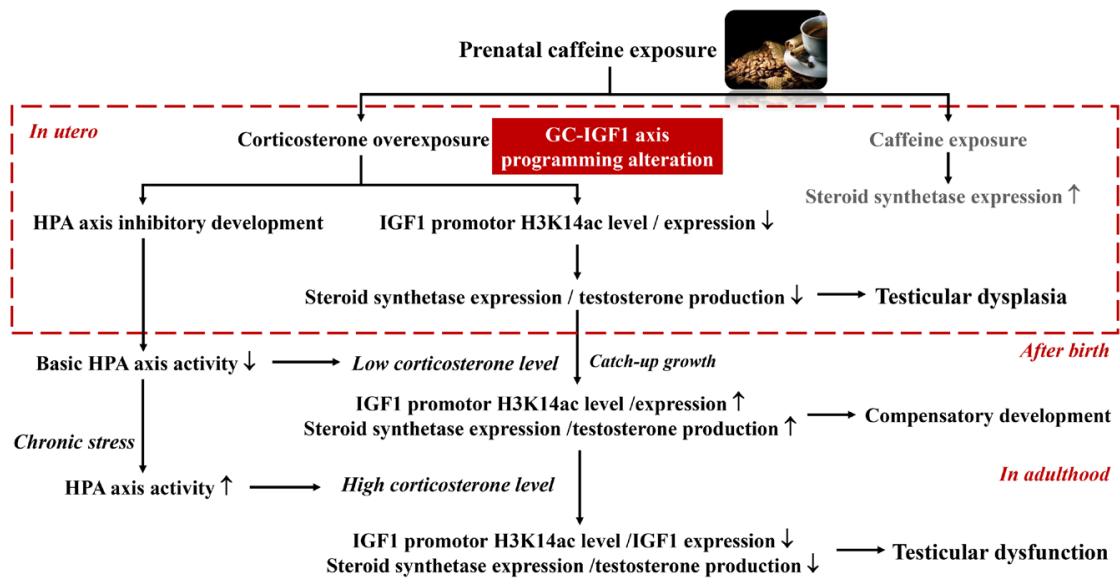
Figure 8
The intrauterine programming alteration of GC-IGF1 axis caused by prenatal caffeine exposure is involved in testicular dysplasia and dysfunction in male offspring rats. GC, glucocorticoid; H3K14ac, histone 3 lysine 14 acetylation; HPA, hypothalamic-pituitary-adrenal; IGF1, insulin-like growth factor 1 . A full colour version of this figure is available at https://doi. org/10.1530/JOE-18-0684.

decreased while the testicular IGF1 expression gradually increased. Intriguingly, when adult offspring (PW12) underwent 2 weeks of chronic stress (ice swimming), the serum corticosterone concentration was elevated and testicular IGF1 expression and testosterone synthesis were markedly inhibited. This negative correlation between the serum corticosterone concentration and testicular IGF1 expression suggested the existence of a 'GC-IGF1 axis' in the testicular development of male PCE offspring. This axis is not only involved in the inhibition of testicular development in utero, but it also mediates postnatal catch-up growth and partial testicular development compensation.

\section{A high level of corticosterone (rather than caffeine) mediated the epigenetic programming mechanism of the GC-IGF1 axis}

Both corticosterone and caffeine have easy access to the fetus through the placenta because of their lipophilicity. Our previous study also demonstrated that high concentrations of corticosterone and caffeine co-existed in the fetal blood following PCE (Wang et al. 2014). Which of these mediated the testicular dysplasia induced by PCE in male offspring rats? Studies have shown that corticosterone can inhibit the expression of IGF1 (Fernandez-Cancio et al. 2008). The actions of glucocorticoid are predominantly mediated by an intracellular receptor, GR (Ramamoorthy \& Cidlowski 2013). GR is widely distributed in different cell types, including LCs (Silva et al. 2010). In vivo, our results showed that $\mathrm{PCE}(\mathrm{H})$ could increase GR expression and decrease IGF1 expression in fetal testes. In vitro, we further confirmed that caffeine and corticosterone have opposite roles for IGF1 expression and steroidogenesis. Specifically, corticosterone inhibited it but caffeine excited it. Thus, it is conceivable that the increased steroid synthetase expression in vivo in the $\mathrm{PCE}(\mathrm{L})$ group should be attributed to the direct effect of caffeine. RU486, a GR inhibitor, can significantly reverse the downregulation of IGF1 expression and steroidogenesis by corticosterone. When we treated the TM3 cells with exogenous IGF1, the inhibitory effect on steroidogenesis caused by corticosterone could also be rescued. All these findings indicated that PCE(H)-induced high corticosterone level (rather than caffeine) inhibited testicular IGF1 expression in the fetus via the GR, which reduced steroid synthetase expression and testosterone production.

Intrauterine overexposure to glucocorticoid can alter fetal developmental programming to adapt to the environment (Harris \& Seckl 2011). The changes in intrauterine programming caused by high glucocorticoid level during pregnancy are likely associated with the epigenetic regulation of important genes (Drake et al. 2011, Crudo et al. 2013). H3K14ac, which is an epigenetic hallmark of transcriptionally active chromatin, participates in regulating the pluripotency and reprogramming capacity of cells (Jayani et al. 2010, Zhang et al. 2016). Bachagol et al. found that the increase in $I g f 1$ expression was related to an increase in its H3K14ac level in the liver (Bachagol et al. 2018). In the present study, we found that the H3K14ac level of the Igf1 promoter decreased at GD20 and PW2 under high corticosterone conditions, but was close to the normal at PW6 and PW12. However, when chronic stress induced an elevated serum corticosterone concentration, the H3K14ac level of the Igf1 promoter region and IGF1 expression decreased. Moreover, we further confirmed in vitro that corticosterone reduced the H3K14ac level in the $I g f 1$ promoter, which was reversed by the GR inhibitor RU486. These results provide evidence that corticosterone negatively regulates H3K14ac and the expression levels of IGF1 via GR. https://joe.bioscientifica.com https://doi.org/10.1530/JOE-18-0684
(C) 2019 Society for Endocrinology Published by Bioscientifica Ltd.
Printed in Great Britain 


\section{Conclusion}

In this study, we confirmed that PCE could lead to testicular dysplasia and dysfunction before and after birth in male offspring rats. The intrauterine programming mechanism behind this relationship is as follows: the high level of glucocorticoid caused by PCE decreases the H3K14ac level and expression of IGF1 through GR, which further contributes to testicular dysplasia and dysfunction. Moreover, the corticosterone-dependent regulation on the H3K14ac level of the Igf1 promoter and its expression were involved in testicular development after birth (Fig. 8). Therefore, we first proposed a 'GC-IGF1 axis' programming mechanism for PCE-induced testicular dysplasia. This in-depth molecular mechanism requires further study in the future. This work will provide an experimental and theoretical basis for the intrauterine origin and therapeutic targets of testicular developmental toxicity-related diseases.

\section{Supplementary data}

This is linked to the online version of the paper at https://doi.org/10.1530/ JOE-18-0684.

\section{Declaration of interest}

The authors declare that there is no conflict of interest that could be perceived as prejudicing the impartiality of the research reported.

\section{Funding}

This work was supported by grants from the National Key Research and Development Program of China (2017YFC1001300), the National Natural Science Foundation of China (Nos. 81430089, 81673524) and Hubei Province Health and Family Planning Scientific Research Project (No. WJ2017C0003)

\section{Author contribution statement}

$\mathrm{H}$ W conceived and designed the experiments. $\mathrm{L} G \mathrm{P}$ and $\mathrm{Q} Z \mathrm{Z}$ did experimental work and paper writing. $C Y, M L$ and $Y F Z$ were contributed to materials, experiments and analysis tools. F L, D J L and S Z were involved in technical assistance, discussion and consulting. All authors reviewed the manuscript.

\section{References}

Aiken CE \& Ozanne SE 2014 Transgenerational developmental programming. Human Reproduction Update 20 63-75. (https://doi. org/10.1093/humupd/dmt043)
Ao Y, Sun Z, Hu S, Zuo N, Li B, Yang S, Xia L, Wu Y, Wang L, He Z, et al. 2015 Low functional programming of renal AT2R mediates the developmental origin of glomerulosclerosis in adult offspring induced by prenatal caffeine exposure. Toxicology and Applied Pharmacology 287 128-138. (https://doi.org/10.1016/j.taap.2015.05.007)

Bachagol D, Joseph GS, Ellur G, Patel K, Aruna P, Mittal M, China SP, Singh RP \& Sharan K 2018 Stimulation of liver IGF-1 expression promotes peak bone mass achievement in growing rats: a study with pomegranate seed oil. Journal of Nutritional Biochemistry 52 18-26. (https://doi.org/10.1016/j.jnutbio.2017.09.023)

CARE Study Group 2008 Maternal caffeine intake during pregnancy and risk of fetal growth restriction: a large prospective observational study. BMI 337 a2332. (https://doi.org/10.1136/bmj.a2332)

Cavalcante FS, Aiceles V, Moraes Dde F, Alves-Pereira JL, Faria TS \& Ramos Cda F 2014 The testis of the mice C57/BL6 offspring in adulthood have alterations due to maternal caffeine consumption. Acta Cirurgica Brasileira 29 16-23. (https://doi.org/10.1590/S010286502014000100003 )

Chen LW, Wu Y, Neelakantan N, Chong MF, Pan A \& van Dam RM 2014 Maternal caffeine intake during pregnancy is associated with risk of low birth weight: a systematic review and dose-response metaanalysis. BMC Medicine 12 174. (https://doi.org/10.1186/s12916-0140174-6)

Chen G, Yuan C, Duan F, Liu Y, Zhang J, He Z, Huang H, He C \& Wang H 2018 IGF1/MAPK/ERK signaling pathway-mediated programming alterations of adrenal cortex cell proliferation by prenatal caffeine exposure in male offspring rats. Toxicology and Applied Pharmacology 341 64-76. (https://doi.org/10.1016/j.taap.2018.01.008)

Cianfarani S, Germani D, Rossi L, Argiro G, Boemi S, Lemon M, Holly JM \& Branca F 1998 IGF-I and IGF-binding protein-1 are related to cortisol in human cord blood. European Journal of Endocrinology 138 524-529. (https://doi.org/10.1530/eje.0.1380524)

Cohen PG 1999 The hypogonadal-obesity cycle: role of aromatase in modulating the testosterone-estradiol shunt - a major factor in the genesis of morbid obesity. Medical Hypotheses 52 49-51. (https://doi. org/10.1054/mehy.1997.0624)

Crudo A, Suderman M, Moisiadis VG, Petropoulos S, Kostaki A, Hallett M, Szyf M \& Matthews SG 2013 Glucocorticoid programming of the fetal male hippocampal epigenome. Endocrinology 154 1168-1180. (https:// doi.org/10.1210/en.2012-1980)

Dorostghoal M, Erfani Majd N \& Nooraei P 2012 Maternal caffeine consumption has irreversible effects on reproductive parameters and fertility in male offspring rats. Clinical and Experimental Reproductive Medicine 39 144-152. (https://doi.org/10.5653/ cerm.2012.39.4.144)

Drake AJ, Liu L, Kerrigan D, Meehan RR \& Seckl JR 2011 Multigenerational programming in the glucocorticoid programmed rat is associated with generation-specific and parent of origin effects. Epigenetics 6 1334-1343. (https://doi.org/10.4161/epi.6.11.17942)

Dupont C, Cordier AG, Junien C, Mandon-Pepin B, Levy R \& ChavattePalmer P 2012 Maternal environment and the reproductive function of the offspring. Theriogenology 78 1405-1414. (https://doi. org/10.1016/j.theriogenology.2012.06.016)

Engelbregt MJ, van Weissenbruch MM, Popp-Snijders C, Lips P \& Delemarre-van de Waal HA 2001 Body mass index, body composition, and leptin at onset of puberty in male and female rats after intrauterine growth retardation and after early postnatal food restriction. Pediatric Research 50 474-478. (https://doi. org/10.1203/00006450-200110000-00009)

Fernandez-Cancio M, Esteban C, Carrascosa A, Toran N, Andaluz P \& Audi L 2008 IGF-I and not IGF-II expression is regulated by glucocorticoids in human fetal epiphyseal chondrocytes. Growth Hormone and IGF Research 18 497-505. (https://doi.org/10.1016/j.ghir.2008.04.004)

Finkielstain GP, Lui JC \& Baron J 2013 Catch-up growth: cellular and molecular mechanisms. World Review of Nutrition and Dietetics 106 100-104. (https://doi.org/10.1159/000342535) 
Fortier I, Marcoux S \& Beaulac-Baillargeon L 1993 Relation of caffeine intake during pregnancy to intrauterine growth retardation and preterm birth. American Journal of Epidemiology 137 931-940. (https:// doi.org/10.1093/oxfordjournals.aje.a116763)

Fowden AL, Forhead AJ, Coan PM \& Burton GJ 2008 The placenta and intrauterine programming. Journal of Neuroendocrinology 20 439-450. (https://doi.org/10.1111/j.1365-2826.2008.01663.x)

Francois I, de Zegher F, Spiessens C, D'Hooghe T \& Vanderschueren D 1997 Low birth weight and subsequent male subfertility. Pediatric Research 42 899-901. (https://doi.org/10.1203/00006450-19971200000029)

Fredholm BB, Battig K, Holmen J, Nehlig A \& Zvartau EE 1999 Actions of caffeine in the brain with special reference to factors that contribute to its widespread use. Pharmacological Reviews 51 83-133.

Fu Q, Yu X, Callaway CW, Lane RH \& McKnight RA 2009 Epigenetics: intrauterine growth retardation (IUGR) modifies the histone code along the rat hepatic IGF-1 gene. FASEB Journal 23 2438-2449. (https://doi.org/10.1096/fj.08-124768)

Greenwood DC, Thatcher NJ, Ye J, Garrard L, Keogh G, King LG \& Cade JE 2014 Caffeine intake during pregnancy and adverse birth outcomes: a systematic review and dose-response meta-analysis. European Journal of Epidemiology 29 725-734. (https://doi.org/10.1007/ s10654-014-9944-x)

Guilbert JJ 2003 The world health report 2002 - reducing risks, promoting healthy life. Education for Health 16 230. (https://doi.org/1 $0.1080 / 1357628031000116808)$

Harris A \& Seckl J 2011 Glucocorticoids, prenatal stress and the programming of disease. Hormones and Behavior 59 279-289. (https:// doi.org/10.1016/j.yhbeh.2010.06.007)

Hediger ML, Overpeck MD, Maurer KR, Kuczmarski RJ, McGlynn A \& Davis WW 1998 Growth of infants and young children born small or large for gestational age: findings from the third National Health and Nutrition Examination Survey. Archives of Pediatrics and Adolescent Medicine 152 1225-1231. (https://doi.org/10.1001/ archpedi.152.12.1225)

Hu GX, Lin H, Chen GR, Chen BB, Lian QQ, Hardy DO, Zirkin BR \& Ge RS 2010 Deletion of the Igf1 gene: suppressive effects on adult Leydig cell development. Journal of Andrology 31 379-387. (https:// doi.org/10.2164/jandrol.109.008680)

Jayani RS, Ramanujam PL \& Galande S 2010 Studying histone modifications and their genomic functions by employing chromatin immunoprecipitation and immunoblotting. Methods in Cell Biology 98 35-56. (https://doi.org/10.1016/S0091-679X(10)98002-3)

Jensen RB, Juul A, Larsen T, Mortensen EL \& Greisen G 2015 Cognitive ability in adolescents born small for gestational age: associations with fetal growth velocity, head circumference and postnatal growth. Early Human Development 91 755-760. (https://doi.org/10.1016/j. earlhumdev.2015.08.014)

Kajantie E 2003 Insulin-like growth factor (IGF)-I, IGF binding protein (IGFBP)-3, Phosphoisoforms of IGFBP-1 and postnatal growth in verylow-birth-weight infants. Hormone Research 60 124-130. (https://doi. org/10.1159/000074513)

Kluger J 2004 The buzz on caffeine. Time 16452.

Luo H, Deng Z, Liu L, Shen L, Kou H, He Z, Ping J, Xu D, Ma L, Chen L, et al. 2014 Prenatal caffeine ingestion induces transgenerational neuroendocrine metabolic programming alteration in second generation rats. Toxicology and Applied Pharmacology 274 383-392. (https://doi.org/10.1016/j.taap.2013.11.020)

Macleod DJ, Sharpe RM, Welsh M, Fisken M, Scott HM, Hutchison GR, Drake AJ \& van den Driesche S 2010 Androgen action in the masculinization programming window and development of male reproductive organs. International Journal of Andrology 33 279-287. (https://doi.org/10.1111/j.1365-2605.2009.01005.x)

Main KM, Jensen RB, Asklund C, Hoi-Hansen CE \& Skakkebaek NE 2006 Low birth weight and male reproductive function. Hormone Research 65 (Supplement 3) 116-122. (https://doi.org/10.1159/000091516)
Moisiadis VG \& Matthews SG 2014a Glucocorticoids and fetal programming part 1: outcomes. Nature Reviews: Endocrinology 10 391-402. (https://doi.org/10.1038/nrendo.2014.73)

Moisiadis VG \& Matthews SG 2014b Glucocorticoids and fetal programming part 2: mechanisms. Nature Reviews: Endocrinology 10 403-411. (https://doi.org/10.1038/nrendo.2014.74)

Moller H \& Skakkebaek NE 1997 Testicular cancer and cryptorchidism in relation to prenatal factors: case-control studies in Denmark. Cancer Causes and Control 8 904-912. (https://doi. org/10.1023/A:1018472530653)

Motohashi M, Wempe MF, Mutou T, Takahashi H, Kansaku N, Ikegami M, Inomata T, Asari M \& Wakui S 2016 Male rats exposed in utero to di(n-butyl) phthalate: age-related changes in Leydig cell smooth endoplasmic reticulum and testicular testosterone-biosynthesis enzymes/proteins. Reproductive Toxicology 59 139-146. (https://doi. org/10.1016/j.reprotox.2015.12.001)

Mylchreest E, Sar M, Wallace DG \& Foster PM 2002 Fetal testosterone insufficiency and abnormal proliferation of Leydig cells and gonocytes in rats exposed to di(n-butyl) phthalate. Reproductive Toxicology 16 19-28. (https://doi.org/10.1016/S08906238(01)00201-5)

Nordenvall AS, Frisen L, Nordenstrom A, Lichtenstein P \& Nordenskjold A 2014 Population based nationwide study of hypospadias in Sweden, 1973 to 2009: incidence and risk factors Journal of Urology 191 783-789. (https://doi.org/10.1016/j. juro.2013.09.058)

Park M, Choi Y, Choi H, Yim JY \& Roh J 2015 High doses of caffeine during the peripubertal period in the rat impair the growth and function of the testis. International Journal of Endocrinology $\mathbf{2 0 1 5}$ 368475. (https://doi.org/10.1155/2015/368475)

Pitteloud N, Hardin M, Dwyer AA, Valassi E, Yialamas M, Elahi D \& Hayes FJ 2005 Increasing insulin resistance is associated with a decrease in Leydig cell testosterone secretion in men. Journal of Clinical Endocrinology and Metabolism 90 2636-2641. (https://doi. org/10.1210/jc.2004-2190)

Ramamoorthy S \& Cidlowski JA 2013 Exploring the molecular mechanisms of glucocorticoid receptor action from sensitivity to resistance. Endocrine Development 24 41-56. (https://doi. org/10.1159/000342502)

Ramlau-Hansen CH, Thulstrup AM, Bonde JP, Olsen J \& Bech BH 2008 Semen quality according to prenatal coffee and present caffeine exposure: two decades of follow-up of a pregnancy cohort. Human Reproduction 23 2799-2805. (https://doi.org/10.1093/humrep/den331)

Reagan-Shaw S, Nihal M \& Ahmad N 2008 Dose translation from animal to human studies revisited. FASEB Journal 22 659-661. (https://doi. org/10.1096/fj.07-9574LSF)

Rivera-Torres J 2015 Analysis of gene and protein expression in atherosclerotic mouse aorta by Western blot and quantitative realtime PCR. Methods in Molecular Biology 1339 309-322. (https://doi. org/10.1007/978-1-4939-2929-0_21)

Shangguan Y, Jiang H, Pan Z, Xiao H, Tan Y, Tie K, Qin J, Deng Y, Chen L \& Wang H 2017 Glucocorticoid mediates prenatal caffeine exposureinduced endochondral ossification retardation and its molecular mechanism in female fetal rats. Cell Death and Disease 8 e3157. (https://doi.org/10.1038/cddis.2017.546)

Signorello LB \& McLaughlin JK 2004 Maternal caffeine consumption and spontaneous abortion: a review of the epidemiologic evidence. Epidemiology 15 229-239. (https://doi.org/10.1097/01. ede.0000112221.24237.0c)

Silva EJ, Queiroz DB, Honda L \& Avellar MC 2010 Glucocorticoid receptor in the rat epididymis: expression, cellular distribution and regulation by steroid hormones. Molecular and Cellular Endocrinology 325 64-77. (https://doi.org/10.1016/j.mce.2010.05.013)

Tan Y, Liu J, Deng Y, Cao H, Xu D, Cu F, Lei Y, Magdalou J, Wu M, Chen L, et al. 2012 Caffeine-induced fetal rat over-exposure to maternal glucocorticoid and histone methylation of liver IGF-1 might https://joe.bioscientifica.com

https://doi.org/10.1530/JOE-18-0684 (c) 2019 Society for Endocrinology Published by Bioscientifica Ltd. Printed in Great Britain 
cause skeletal growth retardation. Toxicology Letters 214 279-287. (https://doi.org/10.1016/j.toxlet.2012.09.007)

Toure A, Lhuillier P, Gossen JA, Kuil CW, Lhote D, Jegou B, Escalier D \& Gacon G 2007 The testis anion transporter 1 (Slc26a8) is required for sperm terminal differentiation and male fertility in the mouse. Human Molecular Genetics 16 1783-1793. (https://doi.org/10.1093/ $\mathrm{hmg} / \mathrm{ddm} 117)$

Wang G \& Hardy MP 2004 Development of Leydig cells in the insulin-like growth factor-I (igf-I) knockout mouse: effects of igf-I replacement and gonadotropic stimulation. Biology of Reproduction $\mathbf{7 0}$ 632-639. (https://doi.org/10.1095/biolreprod.103.022590)

Wang GM, O'Shaughnessy PJ, Chubb C, Robaire B \& Hardy MP 2003 Effects of insulin-like growth factor I on steroidogenic enzyme expression levels in mouse Leydig cells. Endocrinology 144 5058-5064. (https://doi.org/10.1210/en.2003-0563)

Wang L, Shen L, Ping J, Zhang L, Liu Z, Wu Y, Liu Y, Huang H, Chen L \& Wang H 2014 Intrauterine metabolic programming alteration increased susceptibility to non-alcoholic adult fatty liver disease in prenatal caffeine-exposed rat offspring. Toxicology Letters 224 311-318. (https://doi.org/10.1016/j.toxlet.2013.11.006)

Welsh M, Saunders PT, Fisken M, Scott HM, Hutchison GR, Smith LB \& Sharpe RM 2008 Identification in rats of a programming window for reproductive tract masculinization, disruption of which leads to hypospadias and cryptorchidism. Journal of Clinical Investigation 118 1479-1490. (https://doi.org/10.1172/JCI34241)
Welsh M, MacLeod DJ, Walker M, Smith LB \& Sharpe RM 2010 Critical androgen-sensitive periods of rat penis and clitoris development. International Journal of Andrology 33 e144-e152. (https://doi. org/10.1111/j.1365-2605.2009.00978.x)

Xu D, Wu Y, Liu F, Liu YS, Shen L, Lei YY, Liu J, Ping J, Qin J, Zhang C, et al. 2012a A hypothalamic-pituitary-adrenal axis-associated neuroendocrine metabolic programmed alteration in offspring rats of IUGR induced by prenatal caffeine ingestion. Toxicology and Applied Pharmacology 264 395-403. (https://doi.org/10.1016/j. taap.2012.08.016)

Xu D, Zhang B, Liang G, Ping J, Kou H, Li X, Xiong J, Hu D, Chen L, Magdalou J, et al. 2012b Caffeine-induced activated glucocorticoid metabolism in the hippocampus causes hypothalamic-pituitaryadrenal axis inhibition in fetal rats. PLOS ONE 7 e44497. (https://doi. org/10.1371/journal.pone.0044497)

Xu D, Zhang C, He X, Guo Z, Hu D, Lu J, Cheng S \& Wang H 2018 High expression of hippocampal glutamic acid decarboxylase 67 mediates hypersensitivity of the hypothalamic-pituitary-adrenal axis in response to prenatal caffeine exposure in rats. Toxicology Letters $\mathbf{2 8 3}$ 39-51. (https://doi.org/10.1016/j.toxlet.2017.10.019)

Zhang F, Qi B, Wang L, Zhao B, Rode S, Riggan ND, Ecker JR \& Qiao H 2016 EIN2-dependent regulation of acetylation of histone H3K14 and non-canonical histone H3K23 in ethylene signalling. Nature Communications 7 13018. (https://doi.org/10.1038/ ncomms13018)

Received in final form 10 April 2019

Accepted 8 May 2019 (c) 2019 Society for Endocrinology Published by Bioscientifica Ltd. 